\title{
ANALISIS PERFORMANSI ROUTING PROTOKOL DSR, DSDV DAN ZRP PADA MANET MENGGUNAKAN NETWORK SIMULATOR 2
}

\author{
Aris Ismail ${ }^{1}$, Misbah, Nuniek Fahriani \\ 1) Teknik Informatika Universitas Muhammadiyah Gresik \\ Fakultas Teknik,Universitas Muhammadiyah Gresik \\ Jl. Sumatra 101 Gresik Kota Baru (GKB), Randuagung, 61121 Telp.(031) 3951414 , Faks. (0561) 740186 \\ E-mail: arisismail21@gmail.com ${ }^{1)}$
}

\begin{abstract}
ABSTRAK
Routing protokol adalah aturan atau cara pencarian jalur terbaik yang digunakan untuk mengirimkan paket data dari node pengirim ke node penerima. Paket akan melewati beberapa node penghubung melalui mekanisme pembentukan tabel routing. Simulasi dengan menggunakan tools Network Simulator-2 diharapkan dapat membantu menganalisis kemampuan atau kinerja dari masing-masing jenis routing protokol pada kondisi lingkungan jaringan tertentu. Yang nantinya akan didapatkan nilai parameter pengukuran dari routing protokol DSR, DSDV dan ZRP yaitu berupa : Packet Delivery Ratio (PDR), Delay, Konsumsi Energi, Packet Loss, dan Routing Overhead. Analisis performansi dengan melakukan simulasi menggunakan Network Simulator 2 didapatkan hasil parameter konsumsi energi paling hemat pada routing protokol DSDV skenario 10 node dengan 0,9701 joule. Untuk parameter delay mendapatkan hasil $0 \mathrm{~m} / \mathrm{s}$. Sedangkan pada parameter routing overhead pada skenario 100 node mendapatkan hasil 4,6707\%. Pada hasil parameter Packet Delivery Ratio (PDR), ZRP memiliki nilai tertinggi pada parameter ini yaitu pada skenario 20, 50 dan 100 node dengan hasil $100 \%$. Berarti dalam hal keberhasilan routing protokol ZRP dalam mengirimkan paket sangat maksimal, sehingga secara otomatis parameter packet loss akan rendah yaitu $0 \%$.
\end{abstract}

Kata Kunci : $\quad$ MANET, Routing Protokol, DSR, DSDV, ZRP, Network Simulator 2.

\section{PENDAHULUAN}

\subsection{Latar Belakang}

Routing protokol adalah aturan atau cara pencarian jalur terbaik yang digunakan untuk mengirimkan paket data dari node pengirim ke node penerima. Paket akan melewati beberapa node penghubung melalui mekanisme pembentukan tabel routing. Mekanisme protokol routing yang ada di MANET umumnya dikategorikan menjadi 3 jenis yaitu proaktif, reaktif dan hybrid. Protokol ini didesain untuk mendistribusikan informasi yang secara dinamis menyesuaikan kondisi lingkungan jaringan. Dan masing-masing protokol mempunyai cara dan algoritma sendiri berdasarkan jenisnya.

Permasalahan terletak pada proses kinerja yang tidak sama dari masing-masing jenis routing. Dimana untuk jenis routing reaktif berbeda dengan jenis routing proaktif dan hybrid. Routing reaktif memiliki proses pencarian route hanya dilakukan ketika node sumber membutuhkan komunikasi dengan node tujuan. Routing proaktif bekerja dengan cara mendistribusikan routing table ke seluruh jaringan, jadi masing-masing node mempunyai routing table yang lengkap. Sedangkan Protokol routing hybrid adalah metode penggabungan kedua protokol antara routing proaktif dan reaktif.

Kinerja dari masing-masing routing protokol tersebut dapat diketahui salah satunya dengan cara membangun simulasi berdasarkan parameter jaringan yang berfungsi membentuk posisi node dengan tipe routing. Dalam hal ini, pola untuk membangun routing protokol menggunakan perangkat lunak (tools) Network Simulator-2 dengan cara mensimulasikan sesuai kebutuhan jenis routing. DSR termasuk dalam jenis routing protokol reaktif, DSDV termasuk dalam jenis routing protokol proaktif dan ZRP termasuk dalam routing protokol hybrid.

Simulasi dengan menggunakan tools Network Simulator-2 diharapkan dapat membantu menganalisis kemampuan atau kinerja dari masing- 
masing jenis routing protokol pada kondisi lingkungan jaringan tertentu. Yang nantinya akan didapatkan nilai parameter pengukuran dari routing protokol DSR, DSDV dan ZRP yaitu berupa : Packet Delivery Ratio (PDR), Delay, Konsumsi Energi, Packet Loss, dan Routing Overhead.

\subsection{Rumusan Masalah}

Pada penelitian ini terdapat rumusan masalah sebagai berikut :

Bagaimana kinerja dari routing protokol DSR, DSDV dan ZRP pada jaringan MANET dengan menggunakan tools Network Simulator2 ?

\subsection{Tujuan Penelitian}

Adapun tujuan yang ingin dicapai dalam penelitian ini adalah untuk mendapatkan nilai parameter packet delivery ratio, delay, konsumsi energi, packet loss dan routing overhead dengan menggunakan Network Simulator-2.

\section{LANDASAN TEORI \\ 2.1 Mobile Ad-Hoc Network (MANET)}

Mobile Ad Hoc Network (MANET) adalah sebuah jaringan tanpa kabel yang terdiri atas mobile node yang bergerak secara acak. Node-node dalam jaringan ini berfungsi juga sebagai router yang bertanggung jawab untuk mencari dan menangani rute ke setiap node didalam jaringan. Node bergerak bebas secara acak, dengan demikian topologi di jaringan mungkin dapat berubah dengan cepat dan tidak dapat diprediksi. Untuk mengatasi pergerakan ini diperlukan suatu protokol routing yang digunakan untuk menentukan rute antar node agar setiap node dapat berkomunikasi dan bertukar informasi (Rudhyanto, P.F. 2016).

\subsubsection{Karakteristik MANET}

Mobile Ad Hoc Network (MANET) juga memiliki beberapa karakteristik yang lebih menonjol, antara lain (Corson, S. dkk, 1999) :

a. Topologi yang dinamis : Node pada MANET memiliki sifat yang dinamis, yaitu dapat berpindah-pindah kemana saja. Maka topologi jaringan yang bentuknya adalah loncatan antara hop ke hop dapat berubah secara tidak terpola dan terjadi secara terus menerus tanpa ada ketetapan waktu untuk berpindah. Bisa saja didalam topologi tersebut terdiri dari node yang terhubung ke banyak hop lainnya, sehingga sangat berpengaruh secara signifikan terhadap susunan topologi jaringan.

b. Otonomi : Setiap node pada MANET berperan sebagai end-user sekaligus sebagai router yang menghitung sendiri route-path yang selanjutnya akan dipilih.

c. Keterbatasan bandwidth : Link pada jaringan wireless cenderung memiliki kapasitas yang rendah jika dibandingkan dengan jaringan berkabel. Jadi, kapasitas yang keluar untuk komunikasi wireless juga cenderung lebih kecil dari kapasitas maksimum transmisi. Efek yang terjadi pada jaringan yang berkapasitas rendah adalah congestion (kemacetan).

d. Keterbatasan energi : Semua node pada MANET bersifat mobile, sehingga sangat dipastikan node tersebut menggunakan tenaga baterai untuk beroperasi. Sehingga perlu perancangan untuk optimalisasi energi.

e. Keterbatasan Keamanan : Jaringan wireless cenderung lebih rentan terhadap keamanan daripada jaringan berkabel. Kegiatan pencurian (eavesdroping, spoofing dan denial of service) harus lebih diperhatikan.

\subsection{Protokol Routing Pada MANET}

Routing merupakan suatu mekanisme penentuan jalur komunikasi yang menghubungkan dari node pengirim ke node penerima. Untuk melakukan pengiriman data (informasi) tersebut, maka protokol routing akan bertugas untuk menentukan jalur yang akan digunakan untuk mengirimkan data sampai tiba di tempat penerima (Anggraini, S.D., dkk. 2017).

\subsection{DSDV (Destination Sequenced Distance Vector)}

DSDV termasuk dalam kategori table driven routing protokol dalam jaringan Mobile Ad Hoc. DSDV menggunakan metode routing distance vector yang dilengkapi dengan adanya sequence number. Dengan metode distance vector, memungkinkan setiap node dalam jaringan untuk dapat bertukar table routing melalui node tetangganya, namun metode ini dapat mengakibatkan terjadinya looping dalam jaringan sehingga digunakanlah suatu sequence number tertentu untuk mencegah terjadinya looping (Ferdianto, I.A. 2013).

Dalam protokol routing DSDV, sequence number dihasilkan oleh setiap node dalam jaringan yang setiap kali mengirimkan pesan dan terjadinya perubahan dalam jaringan. Hal ini dapat disebabkan karena :

- Update secara periodic oleh masing-masing node dimana setiap node akan mengirimkan pesan secara periodik.

- Jika terdapat node yang bergerak sehingga node tetangga akan mengirimkan pesan ditandai dengan nilai sequence number yang baru.

Dengan metode routing DSDV, setiap node memelihara sebuah table forwarding dan menyebarkan table routing ke node tetangga. Table routing tersebut memuat informasi sebagai berikut :

- Alamat node tujuan.

- Jumlah hop yang diperlukan untuk mencapai node tujuan.

- Sequence number dari informasi yang diterima.

- Install Time 
Table routing akan diperbarui secara periodic dengan tujuan untuk menyesuaikan jika terjadi perubahan topologi jaringan (ada node yang bergerak atau berpindah tempat), dan untuk memelihara konsistensi dari table routing yang sudah ada. Sequence number yang baru akan dihasilkan oleh setiap node jika terjadi pembaruhan table routing.

Jika table routing sudah diperbaharui maka akan dipilih rute untuk mencapai node tujuan dengan kriteria sebagai berikut :

a.Table routing dengan nilai sequence number yang terbaru akan terpilih. Sequence number terbaru ditandai dengan nilai sequence number yang lebih besar dari yang sebelumnya.

b.Jika dihasilkan sequence number yang sama maka dilihat nilai metricnya, dan nilai metric yang paling kecil akan dipilih.

Setiap node akan mempunyai sebuah forwarding table yang berisi informasi pada table routing dan informasi lain seperti install time. Install time akan berisi interval waktu yang diperlukan untuk mendapatkan table routing dari node tujuan. Jika install time bernilai besar, maka hal tersebut mengindikasikan adanya link yang terputus antara node asal dan node tujuan. Install time dijadikan dasar keputusan untuk menghapus rute tertentu yang terputus dengan node asal. Dengan penggunaan DSDV maka penghapusan suatu rute tersebut akan jarang sekali dilakukan namun install time tetap digunakan untuk memonitoring rute-rute yang terputus dengan node asal, dan mengambil langkah yang diperlukan bila hal tersebut terjadi.

Link yang terputus akan ditandai dengan nilai metric yang tak terhingga, dan node asal akan mengeluarkan sequence number ganjil untuk node tujuan tersebut. Sequence number yang ganjil tersebut akan disebarkan ke node-node lain sehingga semua node dalam jaringan tersebut mengetahui bahwa ada link yang terputus untuk node tujuan dengan sequence number ganjil tersebut.

Looping dalam jaringan DSDV dapat dihindari dengan penggunaan sequence number, dimana setiap node untuk setiap perubahan dalam jaringan akan menghasilkan sequenced number baru. Jadi node lain akan mengetahui kejadian yang baru terjadi melalui nilai sequence number. Semakin besar nilai sequence number maka pesan yang diterima semakin baru. Sequence number yang lebih kecil menandakan bahwa kejadian tersebut sudah tidak up to date.

\subsection{DSR (Dynamic Source Routing)}

Dynamic Source Routing (DSR) adalah protokol routing yang efisien dan sederhana dirancang khusus untuk digunakan dalam multi-hop jaringan nirkabel ad hoc mobile. Jaringan sudah mengatur konfigurasi diri sendiri, tidak membutuhkan jaringan infrastruktur atau administrasi. Antara node tidak secara langsung dalam transmisi nirkabel berbagai satu sama lain. Semua routing ditentukan secara otomatis dan dipelihara oleh routing protokol Dynamic Source Routing (DSR). Karena jumlah atau urutan antara hop yang diperlukan untuk mencapai tujuan dapat berubah setiap saat, topologi jaringan yang dihasilkan cukup banyak dan cepat berubah. Protokol Dynamic Source Routing (DSR) memungkinkan node secara dinamis menemukan sumber rute di beberapa jaringan hop dalam jaringan ad hoc (Johnson, dkk. 2001).

Protokol DSR ini terdiri dari dua mekanisme utama, yaitu Route Discovery (pencarian rute) dan Route Maintenance (pemeliharaan rute) (Wahanani, H.E. 2013) :

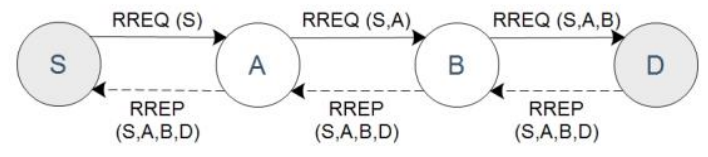

Gambar 1 Mekanisme Protokol DSR (Wahanani, H.E. 2013)

\subsubsection{Mekanisme Route Discovery}

Route discovery adalah suatu mekanisme pada protokol yang berfungsi untuk melakukan pencarian path (jalur) secara dinamis dalam jaringan ad hoc, baik secara langsung di dalam range transmisi ataupun dengan melewati beberapa node intermediate. Penentuan path ini terbagi menjadi dua bagian yaitu Route Request (RREQ) dan Route Reply (RREP).

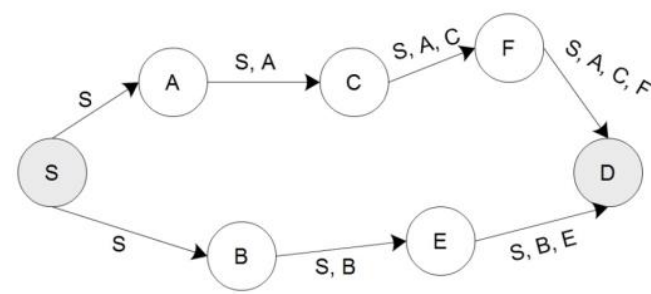

Gambar 2 Route Request (Wahanani, H.E. 2013)

Pada Gambar 2 paket RREQ yang dipancarkan oleh node $\mathrm{S}$ diterima oleh node $\mathrm{B}$. Pada node $\mathrm{B}$, paket RREQ yang diterima diperiksa apakah sebelumnya pernah singgah di B. Karena ternyata paket RREQ tersebut belum pernah singgah di B, maka paket RREQ diforward dengan cara flooding oleh node $\mathrm{B}$. Sebelum diforward, pada paket RREQ disisipi identifier B sehingga pada paket RREQ yang dipancarkan oleh node $\mathrm{B}$ tersebut terdapat catatan $[S, B]$ yang menunjukkan paket RREQ telah menempuh rute $\mathrm{S} \rightarrow \mathrm{B}$. Hal yang sama dilakukan ketika paket RREQ tersebut singgah ke node E. Dengan demikian, ketika paket RREQ tersebut dipancarkan oleh node $\mathrm{E}$, pada paket RREQ terdapat catatan yang berisi [S,B,E] yang menunjukkan paket RREQ tersebut telah menempuh rute $\mathrm{S} \rightarrow \mathrm{B} \rightarrow \mathrm{E}$. begitu pula jika dari $[\mathrm{S}, \mathrm{A}, \mathrm{C}, \mathrm{F}]$ menunjukkan paket RREQ tersebut telah menempuh rute $\mathrm{S} \rightarrow \mathrm{A} \rightarrow \mathrm{C} \rightarrow \mathrm{F}$. 


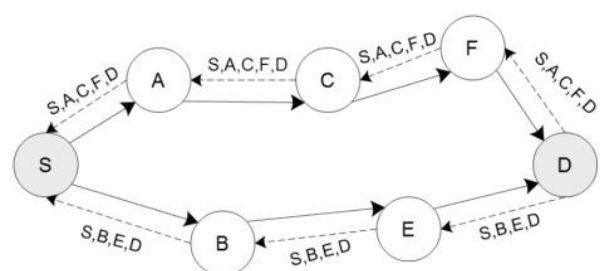

Gambar 3 Route Reply (Wahanani, H.E. 2013)

Pada Gambar 3 ditunjukkan bahwa node D menerima paket RREQ [S,A,C,F,D] dan RREQ [S,B,E,D]. Kemudian node D membalas paket RREQ tersebut dengan RREP [S,A,C,F,D] dan RREP [S,B,E,D] yang dikirim kepada node $\mathrm{S}$. Rute yang ditempuh oleh RREP [S,A,C,F,D] adalah $\mathrm{D} \rightarrow \mathrm{F} \rightarrow \mathrm{C} \rightarrow \mathrm{A} \rightarrow \mathrm{S}$ dan rute yang ditempuh oleh RREP [S,B,E,D] adalah $\mathrm{D} \rightarrow \mathrm{E} \rightarrow \mathrm{B} \rightarrow \mathrm{S}$. Node $\mathrm{S}$ yang menerima RREP [S,A,C,F,D] dan RREP [S,B,E,D] akan mengetahui rute yang harus ditempuh untuk mengirim paket data ke node $\mathrm{D}$. Node $\mathrm{S}$ dapat memilih salah satu rute $\mathrm{S} \rightarrow \mathrm{A} \rightarrow \mathrm{C} \rightarrow \mathrm{F} \rightarrow \mathrm{D}$ atau $\mathrm{S} \rightarrow \mathrm{B} \rightarrow \mathrm{E} \rightarrow \mathrm{D}$ untuk mengirim paket data. Ketika node $\mathrm{S}$ mengirim paket-paket data ke node $\mathrm{D}$, node $\mathrm{S}$ menyisipkan informasi rute yang harus ditempuh oleh paket-paket data tersebut untuk menuju node tujuan D (Wahanani, H.E. 2013).

\subsection{ZRP (Zone Routing Protokol)}

Zone Routing Protokol (ZRP) adalah salah satu dari contoh hybrid routing protokol dan pengertian hybrid routing protokol sendiri adalah kombinasi dari kedua tipe routing protokol yaitu routing protokol proaktif dan routing protokol reaktif. ZRP bekerja berdasarkan zona dengan menggunakan konsep zona terbatas menggunakan fitur dari routing protokol proaktif, sedangkan zona luar menggunakan fitur dari routing protokol reaktif. ZRP terdiri dari dua sub routing protokol utama yaitu Intra Zone Routing Protokol (IARP) dan Inter Zone Routing Protokol (IERP). IARP mengacu pada jaringan padat yang menjadi batas dari zona routing protokol proaktif sedangkan IERP mengacu pada jaringan zona luar dari routing protokol reaktif. IARP mempertahankan informasi topologi jaringan dengan selalu mengupdate jalur ketika node berada didalam zona dan IERP hanya bekerja ketika node tujuan berada diluar zona (Arinatal, Y.A. 2015).

Node yang berada pada jarak maksimum radius yang sudah ditentukan disebut peripheral node, dan node yang berada pada posisi kurang dari radius (berada didalam zona) disebut interior node. Pada Gambar 2.12, Peripheral Node adalah node E, F, G, $\mathrm{K}, \mathrm{M}$ dan Interior Node adalah B, C, D, H, I, J. Node $\mathrm{L}$ berada diluar zona node A (Adiwicaksono, $\mathrm{S}$. 2017).

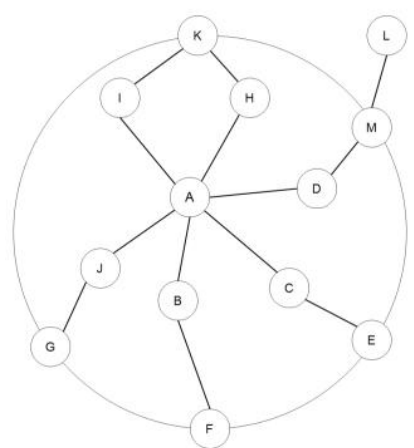

Gambar 4 Contoh Zona Routing Node A Dengan Radius 2 Hop (Adiwicaksono, S. 2017)

Untuk cara kerja pembentukan rute dari ZRP pertama node sumber mengirimkan permintaan rute ke Peripheral Node miliknya. Permintaan rute berisi alamat sumber, alamat tujuan dan sequence number, lalu setiap peripheral node akan mengecek zonanya apakah node tujuan ada di zonanya. Jika pada zona peripheral node tidak terdapat tujuannya, maka peripheral zone akan menambahkan alamatnya kepada paket route-request dan meneruskan paket kepada peripheral nodenya. Jika node tujuan berada didalam zonanya, maka peripheral node akan mengirimkan route reply kembali menuju node sumber. Node sumber menggunakan jalur yang disimpan dalam paket route-reply untuk mengirim paket data ke tujuan. Pada ZRP, protokol routing proaktif lokal (dalam zona) disebut IntrA-zone Routing Protokol (IARP), dan protokol routing reaktif global (diluar zona) disebut IntEr-zone Routing Protokol (IERP). IARP memelihara informasi routing dari node-node yang berada dalam zona routing sebuah node. Route discovery dan route maintenance dilakukan oleh IERP. Bila diperlukan penemuan global, jika topologi zona lokal diketahui, maka hal tersebut bisa digunakan untuk mengurangi lalu lintas. Untuk mem-broadcast paket, ZRP menggunakan konsep Bordercasting, yang layanannya disediakan oleh Bordercasting Resolution Protokol (BRP) (Adiwicaksono, S. 2017).

\section{III.ANALISIS DAN PERANCANGAN SISTEM}

\subsection{Analisis sistem}

Jenis jaringan wireless memiliki keterbatasan jangkauan transmisi, sehingga menyebabkan penggunaan routing dibutuhkan untuk mengirim data melalui jaringan. penggunaan mobile node dalam wireless sendiri menimbulkan masalah dalam routing. Protokol routing konvensional tidak didesain untuk topologi dinamis. Oleh karena itu muncullah berbagai jenis protokol routing yang mampu untuk mengatasi hal tersebut (Khristian, E. 2013).

Dynamic Source Routing (DSR) dalam melakukan pengiriman paket data dari sumber ke tujuan memerlukan proses route discovery dan route maintenance. Pada route discovery terdapat dua 
kegiatan RREQ dan RREP. RREQ dilakukan ketika node sumber tidak mengetahui rute menuju node tujuan. RREP merupakan respon node tujuan ketika adanya permintaan rute dari node sumber. DSR termasuk dalam jenis routing protokol reaktif, dimana pada proses pencarian rute hanya dilakukan ketika node sumber membutuhkan komunikasi dengan node tujuan. Destination Sequenced Distance Vector (DSDV) dalam melakukan pengiriman paket data dari sumber ke tujuan dengan melihat rute berdasarkan tabel routing yang ada. Dalam tabel routing tersebut terdapat informasi rute menuju node tujuan. DSDV termasuk dalam jenis routing protokol proaktif, dimana pada protokol ini setiap node melakukan broadcast tabel routing ke semua node dalam jaringan walaupun tidak ada permintaan rute. Zone Routing Protokol (ZRP) bekerja berdasarkan zona dengan menggunakan konsep zona terbatas menggunakan fitur dari routing protokol proaktif, sedangkan zona luar menggunakan fitur dari routing protokol reaktif. ZRP terdiri dari dua sub routing protokol utama yaitu Intra Zone Routing Protokol (IARP) dan Inter Zone Routing Protokol (IERP).

Ketiga jenis protokol routing tersebut memiliki karakteristik yang berbeda dalam melakukan proses routing karena adanya perbedaan jenis protokol routing sehingga memiliki kinerja yang berbeda. Maka diperlukan analisis parameter pengukuran untuk mengetahui kinerja dari protokol routing tersebut.

\subsection{Hasil Analisis}

Bahwa untuk mengetahui hasil kinerja dari routing protokol DSR, DSDV, dan ZRP melalui proses simulasi dengan network simulator 2 yaitu berupa perancangan pembentukan pola pergerakan node dan pembentukan pola trafik. Selanjutnya dilakukan penghitungan terhadap parameter pengukuran menggunakan file.awk untuk mengetahui kinerjanya dari masing-masing routing protokol yang meliputi packet delivery ratio, delay, konsumsi energi, packet loss, dan routing overhead. Untuk lebih jelasnya dapat dilihat pada gambar 3.1 berikut ini :

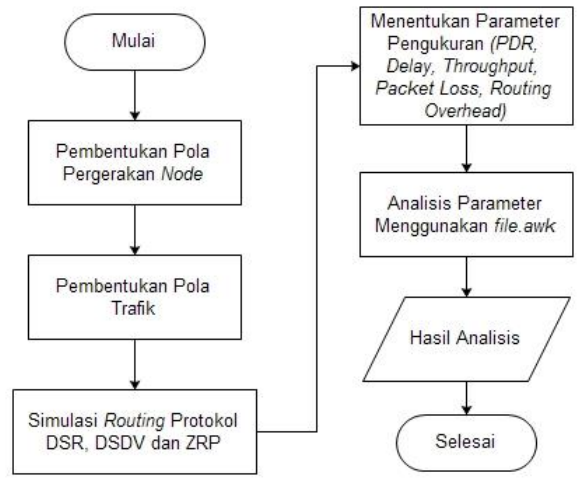

Gambar 5 Diagram Alir Analisis Routing
Pada algoritma ini ada 3 jenis routing protokol yang akan dianalisis yaitu routing protokol DSR, DSDV, dan ZRP. Masing-masing dari routing protokol tersebut memiliki diagram alir yang berbeda. Berikut ini merupakan penjelasan algoritma tersebut :

\subsubsection{Algoritma Routing DSR}

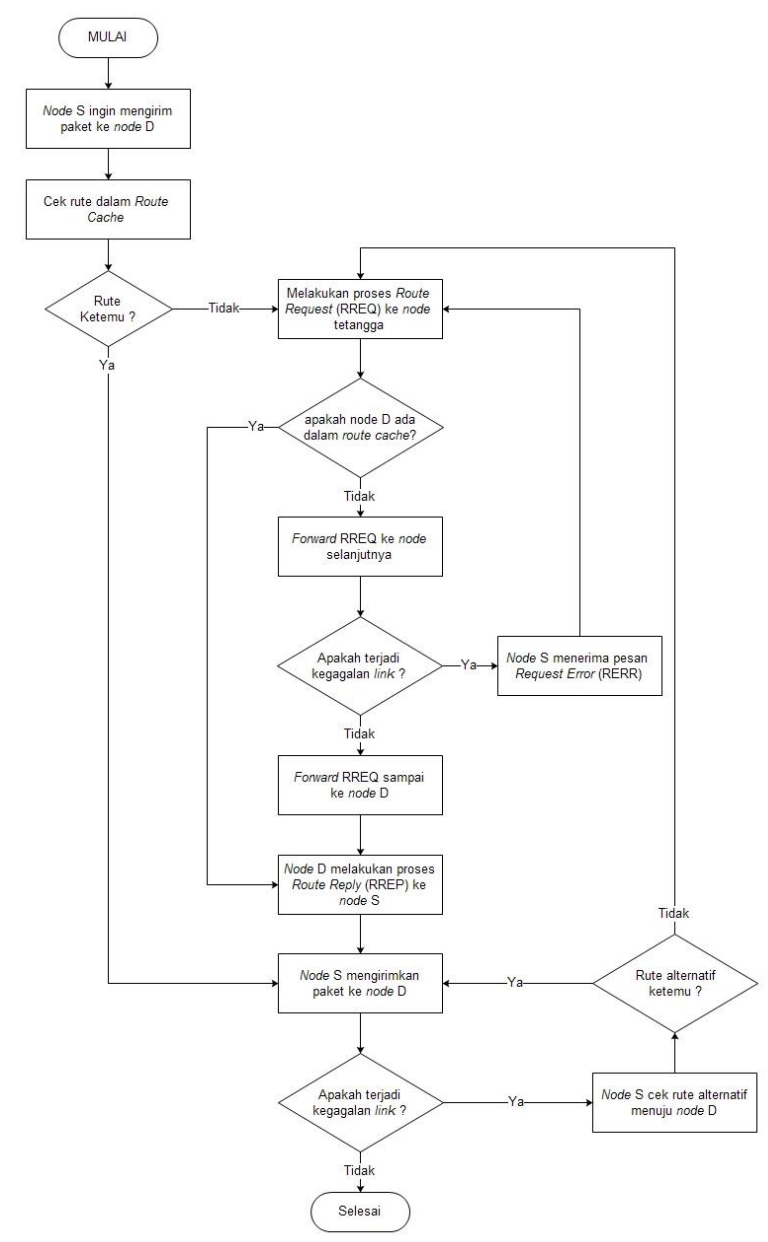

Penjelasan gambar 6:

Gambar 6 Flowchart DSR

Dimulai dari node $\mathrm{S}$ (source) yang ingin mengirimkan paket data ke node $\mathrm{D}$ (destination). Node $\mathrm{S}$ mengecek route cachenya apakah terdapat rute menuju ke node $\mathrm{D}$. Jika node $\mathrm{S}$ memiliki rute menuju node $\mathrm{D}$, maka node $\mathrm{S}$ akan mengirim paket data ke node $\mathrm{D}$ tanpa melakukan RREQ. Jika node $\mathrm{S}$ tidak memiliki rute ke node $\mathrm{D}$, maka node $\mathrm{S}$ akan melakukan proses Route Request (RREQ) ke node tetangga. Node $\mathrm{S}$ mengirimkan paket menuju node $\mathrm{D}$, jika ditengah perjalanan pengiriman paket terjadi kegagalan link atau link terputus, maka node $\mathrm{S}$ akan mengirimkan paket melalui rute alternatif yang sudah tersimpan dalam route cache. Jika node tidak ada yang memiliki rute alternatif menuju node $\mathrm{D}$, maka node $\mathrm{S}$ akan melakukan proses RREQ ulang. Jika tidak terjadi kegagalan link, maka paket akan sampai ke tujuan yaitu node D.

\subsection{Perancangan Algoritma Routing}




\subsubsection{Algoritma Routing DSDV}

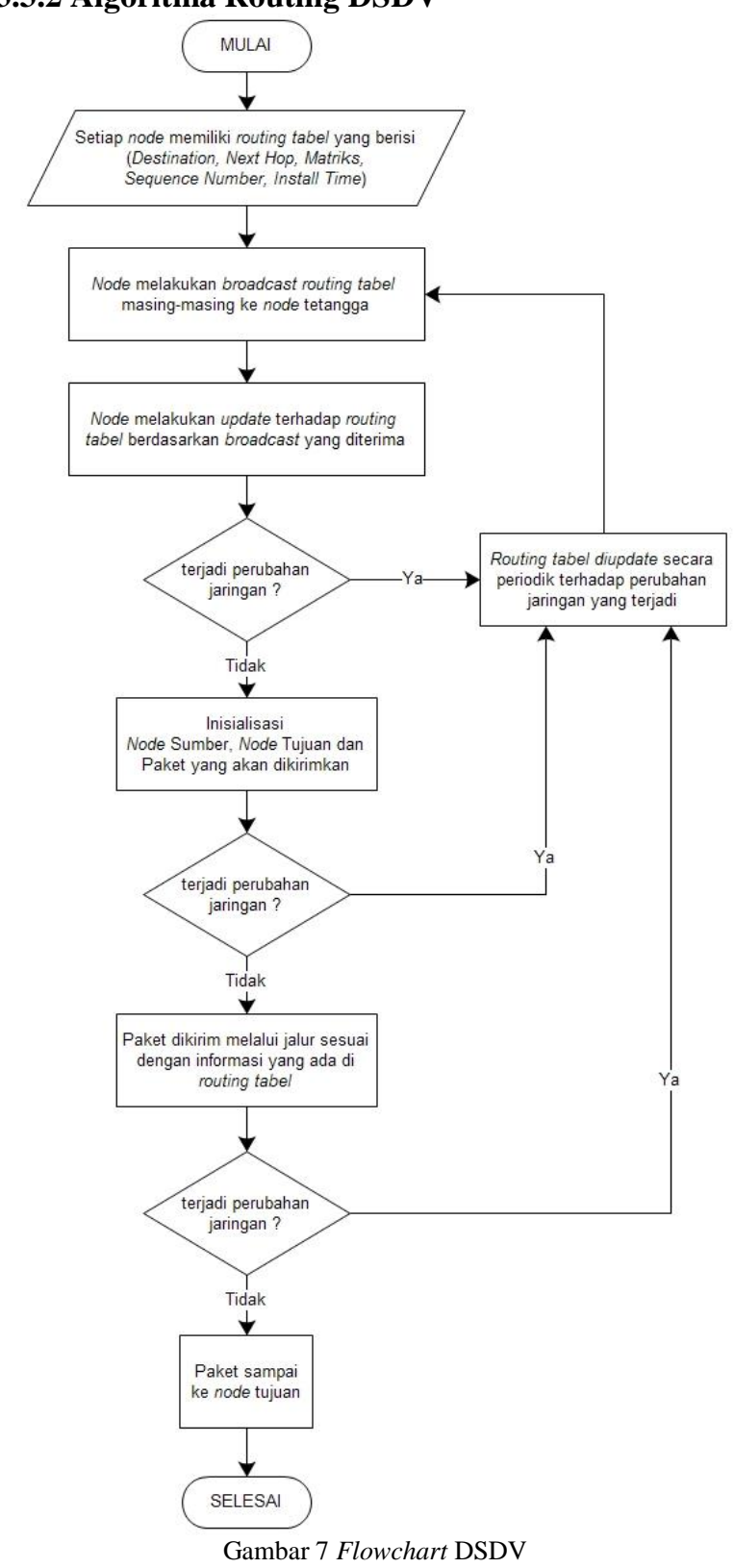

Penjelasan Gambar 7 :

Setiap node dalam jaringan memiliki routing tabel masing-masing yang berisi (Node Destination, Next Hop, Matriks, Sequence Number dan Install Time). Node melakukan broadcast routing tabel ke node tetangga dengan tujuan agar semua node dalam jaringan tersebut mengetahui jarak antar node. Node akan melakukan update terhadap routing tabel berdasarkan Paket akan dikirim melalui jalur sesuai dengan informasi yang ada dalam routing tabel. Jika terjadi perubahan jaringan, maka node tersebut akan melakukan update terhadap routing tabelnya dan melakukan broadcast ke node tetangga dengan tujuan agar node lain mengetahui routing tabel yang baru. Paket akan diteruskan sampai menuju ke node tujuan.

\subsubsection{Algoritma Routing ZRP}

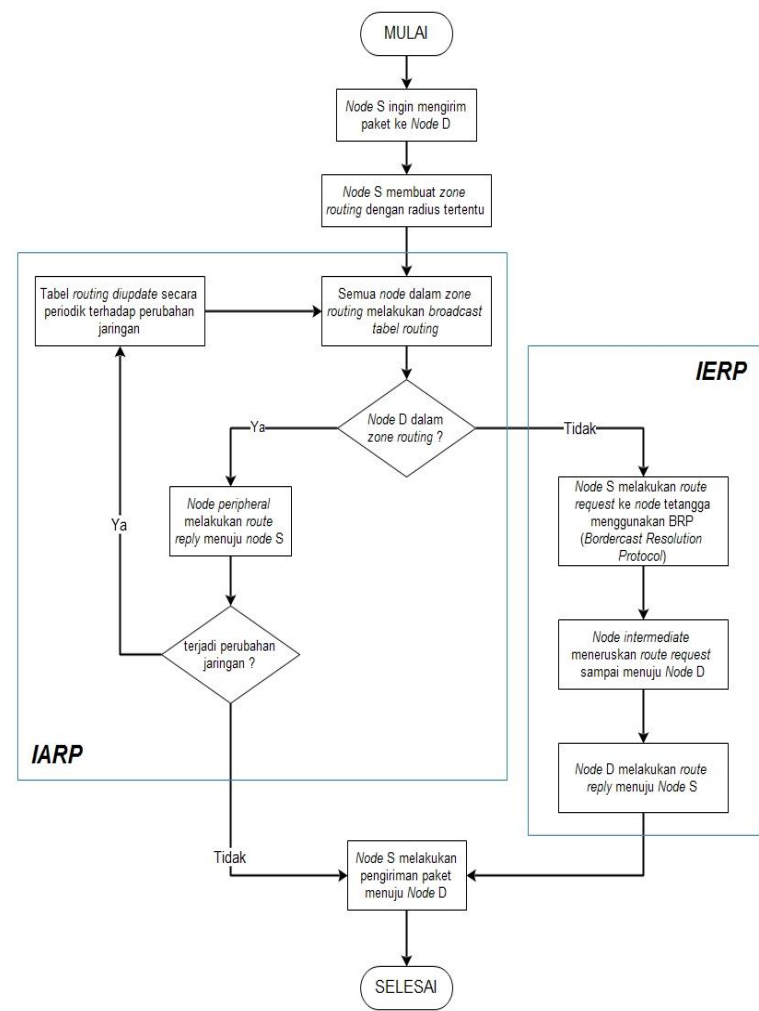

Gambar 8 Flowchart ZRP

Penjelasan Gambar 8:

Dimulai dari node S (Source) ingin mengirimkan paket menuju node D (Destination). Node $\mathrm{S}$ membuat zona routing dengan radius hop (loncatan) tertentu. Pada wilayah dalam zona routing ini disebut dengan Intra Zone Routing Protocol (IARP). Dalam IARP, semua node yang tercakup di zona routing melakukan proses broadcast tabel routing ke semua node agar memiliki informasi rute dalam zona tersebut. Jika node $\mathrm{D}$ berada didalam zona routing tersebut, maka node peripheral akan memberi informasi kepada node $\mathrm{S}$ dengan cara melakukan route reply. Jika terjadi perubahan jaringan maka tabel routing akan diupdate secara periodic dengan cara setiap node melakukan broadcast tabel routing untuk memperbarui informasi. Jika tidak terjadi perubahan jaringan maka node $\mathrm{S}$ akan melakukan pengiriman paket menuju node $\mathrm{D}$ dan selesai. Jika node $\mathrm{D}$ berada diluar zona routing, maka perlu dilakukan pencarian rute dimana proses ini termasuk dalam wilayah tanggung jawab Inter Zone Routing Protocol (IERP). Dalam IERP, node $\mathrm{S}$ melakukan proses pencarian rute dengan cara melakukan proses route request ke node tetangga menggunakan layanan $\mathrm{BRP}$ (Bordercast Resolution Protocol). Node intermediate atau node yang menerima route request akan meneruskannya sampai menuju ke node $\mathrm{D}$. Jika route request sudah sampai pada node $\mathrm{D}$, selanjutnya node $\mathrm{D}$ akan membalas dengan melakukan route reply menuju node $\mathrm{S}$ dengan menyertakan informasi berupa rute mana 
saja yang dapat dilewati. Node $\mathrm{S}$ akan memutuskan untuk memilih melewati rute yang terpendek dan mengirimkan paket menuju ke node D. Paket akan sampai ke Node D dan selesai.

\subsection{Parameter Pengukuran}

Berikut ini merupakan beberapa parameter yang digunakan untuk menguji performansi routing protokol DSR, DSDV, dan ZRP yaitu (Sasongko, S.A., dkk. 2012) :

1. Packet Delivery Ratio (PDR)

Packet Delivery Ratio merupakan perbandingan banyaknya jumlah paket yang diterima oleh node penerima dengan total paket yang dikirimkan dalam suatu periode waktu tertentu atau bisa juga dihitung dengan cara mengurangi jumlah paket keseluruhan yang dikirim dengan paket yang hilang. Secara sistematis Packet Delivery Ratio dapat dihitung dengan persamaan berikut :

2. Delay

$$
\mathrm{PDR}=\frac{\sum \text { data yang diterima }}{\sum \text { data yang dikirim }} \times 100 \%
$$

Delay adalah jumlah total waktu pengiriman paket dalam satu kali pengamatan. Dalam hal ini satu kali simulasi dibagi dengan jumlah usaha pengiriman yang berhasil dalam satu kali pengamatan tersebut. Secara umum delay rata-rata dapat dinyatakan dengan persamaan berikut :

Average Delay $=\frac{\text { total delay }}{\text { total paket yang diterima }}$

\section{Dimana}

Total Delay $=$ Waktu Paket Diterima - Waktu Paket Dikirim

\section{Konsumsi Energi}

Merupakan jumlah energi yang dibutuhkan oleh node untuk melakukan proses transmisi data pada sebuah jaringan. Secara umum konsumsi energi dinyatakan dalam persamaan berikut :

$$
\text { Energi }=\frac{\text { total jumlah energi }}{\text { jumlah node }} \times 100
$$

\section{Packet Loss}

Packet Loss merupakan banyaknya jumlah paket yang hilang selama proses pengiriman paket dari node asal menuju node tujuan. (Sidharta, Y., dkk. 2013). Packet loss dapat dihitung dengan persamaan berikut :

\section{Packet Loss}

$$
=
$$

$\frac{\sum \text { paket yang dikirim- } \sum \text { paket yang diterima }}{\sum \text { paket yang dikirim }} \times 100 \%$

\section{Routing Overhead}

Routing overhead merupakan rasio antara jumlah paket routing dengan paket data yang berhasil diterima. Routing overhead dapat dihitung dengan persamaan berikut (Dhamayanti, Y., dkk. 2013) :

$$
\begin{gathered}
\text { Routing Overhead }= \\
\frac{\sum \text { paket routing }}{\sum \text { paket data yang diterima }}
\end{gathered}
$$

\section{IMPLEMENTASI DAN PENGUJIAN SISTEM}

Implementasi sistem adalah implementasi dari analisa dan desain sistem yang telah dibuat sebelumnya. Sehingga diharapkan dengan adanya implementasi ini dapat dipahami jalannya suatu routing protokol DSR, DSDV dan ZRP menggunakan simulasi dengan software Network Simulator 2 versi 2.35 .

\subsection{Hasil Pengujian Sistem}

Pengujian sistem digunakan untuk mengetahui hasil performansi jaringan dari setiap masing-masing protokol routing. Pada pengujian ini dilakukan ujicoba empat kali, yaitu dengan 10 node, 20 node, 50 node dan 100 node. Dan dilakukan analisa dengan beberapa parameter pengukuran yang telah ditentukan, yaitu : konsumsi energi, delay, packet delivery ratio, packet loss dan routing overhead. Berikut adalah data yang diperoleh selama proses simulasi terhadap protokol routing DSR, DSDV dan ZRP.

\subsubsection{Hasil Simulasi DSR}

\begin{tabular}{|c|c|c|c|c|c|}
\hline $\begin{array}{c}\text { Protokol } \\
\text { Routing }\end{array}$ & Parameter & \multicolumn{4}{|c|}{ Jumlah Node } \\
\cline { 3 - 6 } & $\begin{array}{c}\text { Konsumsi } \\
\text { Energi } \\
\text { (Joule) }\end{array}$ & 100,0000 & 17,6587 & 17,0173 & 100,0000 \\
\cline { 2 - 6 } & $\begin{array}{c}\text { Packet } \\
\text { Delivery } \\
\text { Ratio(\%) }\end{array}$ & 0,1345 & 0,0265 & 34,2995 & 42,5000 \\
\cline { 2 - 6 } & $\begin{array}{c}\text { Average } \\
\text { End-to-End } \\
\text { Delay(m/s) }\end{array}$ & 907,2559 & 19,4383 & 11,8511 & 18,0687 \\
\cline { 2 - 6 } & $\begin{array}{c}\text { Packet } \\
\text { Loss(\%) }\end{array}$ & 99,8655 & 99,9735 & 65,7005 & 57,5000 \\
\cline { 2 - 6 } & $\begin{array}{c}\text { Routing } \\
\text { Overhead(\%) }\end{array}$ & 60,0000 & 37,5000 & 9,2697 & 5,0712 \\
\hline
\end{tabular}

Tabel 1 Hasil Simulasi DSR

Pada tabel 1 menunjukkan hasil simulasi protokol routing DSR, dimana konsumsi energi yang dibutuhkan pada kapasitas 50 node lebih hemat dengan nilai sebesar 17,0173 joule. Pada parameter packet delivery ratio menunjukkan dengan kapasitas 100 node memiliki nilai tertinggi yaitu 42,50000\%. Pada parameter average end-to-end delay menunjukkan jaringan dengan kapasitas 50 node memiliki delay terendah yaitu sebesar $11,8511 \mathrm{~m} / \mathrm{s}$. 
Pada parameter packet loss kapasitas 100 node memiliki nilai terendah yaitu sebesar 57,5000\%. Sedangkan pada parameter routing overhead menunjukkan kapasitas 100 node memiliki nilai terendah yaitu sebesar 5,0712\%.

4.1.2 Hasil Simulasi DSDV

\begin{tabular}{|c|c|c|c|c|c|}
\hline \multirow{1}{*}{$\begin{array}{c}\text { Protokol } \\
\text { Routing }\end{array}$} & Parameter & \multicolumn{4}{|c|}{ Jumlah Node } \\
\cline { 3 - 6 } & $\begin{array}{c}\text { Konsumsi } \\
\text { Energi } \\
\text { (Joule) }\end{array}$ & 0,9701 & 1,9697 & 4,9640 & 9,9301 \\
\cline { 2 - 6 } & $\begin{array}{c}\text { Packet } \\
\text { Delivery } \\
\text { Ratio(\%) }\end{array}$ & 0,0000 & 1,7544 & 1,5196 & 0,2469 \\
\cline { 2 - 6 } & $\begin{array}{c}\text { Average } \\
\text { End-to-End } \\
\text { Delay(m/s) }\end{array}$ & 0,0000 & 0,0000 & 0,0000 & 0,0000 \\
\cline { 2 - 6 } & $\begin{array}{c}\text { Packet } \\
\text { Loss(\%) }\end{array}$ & 100,000 & 98,2456 & 98,4804 & 99,7531 \\
\cline { 2 - 6 } & $\begin{array}{c}\text { Routing } \\
\text { Overhead(\%) }\end{array}$ & 40,000 & 19,4030 & 7,7170 & 4,6707 \\
\hline
\end{tabular}

Tabel 2 Hasil Simulasi DSDV

Pada tabel 2 menunjukkan hasil simulasi protokol routing DSDV, dimana konsumsi energi yang dibutuhkan pada kapasitas 10 node lebih hemat dengan nilai sebesar 0,9701 joule. Pada parameter packet delivery ratio menunjukkan dengan kapasitas 20 node memiliki nilai tertinggi yaitu $1,7544 \%$. Pada parameter average end-to-end delay semua jaringan menunjukkan sebesar $0,0000 \mathrm{~m} / \mathrm{s}$. Pada parameter packet loss kapasitas 20 node memiliki nilai terendah yaitu sebesar $98,2456 \%$. Sedangkan pada parameter routing overhead menunjukkan kapasitas 100 node memiliki nilai terendah yaitu sebesar $4,6707 \%$.

\subsubsection{Hasil Simulasi ZRP}

\begin{tabular}{|c|c|c|c|c|c|}
\hline \multirow{1}{*}{$\begin{array}{c}\text { Protokol } \\
\text { Routing }\end{array}$} & \multirow{2}{*}{ Parameter } & \multicolumn{4}{|c|}{ Jumlah Node } \\
\cline { 3 - 6 } & $\begin{array}{c}\text { Konsumsi } \\
\text { Energi } \\
\text { (Joule) }\end{array}$ & 4,7328 & 1,9787 & 7,3318 & 9,9073 \\
\cline { 2 - 6 } & $\begin{array}{c}\text { Packet } \\
\text { Delivery } \\
\text { Ratio(\%) }\end{array}$ & 0,0000 & 100,000 & 100,000 & 100,000 \\
\cline { 2 - 6 } & $\begin{array}{c}\text { Average } \\
\text { End-to-End } \\
\text { Delay(m/s) }\end{array}$ & 0,0000 & 8,1465 & 7,4076 & 23,4693 \\
\cline { 2 - 6 } & $\begin{array}{c}\text { Packet } \\
\text { Loss(\%) }\end{array}$ & 100,0000 & 0,0000 & 0,0000 & 0,0000 \\
\cline { 2 - 6 } & $\begin{array}{c}\text { Routing } \\
\text { Overhead(\%) }\end{array}$ & 39,2157 & 23,1183 & 11,5614 & 5,3674 \\
\hline
\end{tabular}

Tabel 3 Hasil Simulasi ZRP

Pada tabel 3 menunjukkan hasil simulasi protokol routing ZRP, dimana konsumsi energi yang dibutuhkan pada kapasitas 20 node lebih hemat dengan nilai sebesar 1,9787 joule. Pada parameter packet delivery ratio dengan kapasitas 20, 50 dan 100 node sama-sama memiliki nilai tertinggi yaitu $100,0000 \%$. Pada parameter average end-to-end delay menunjukkan dengan kapasitas 100 node memiliki nilai sebesar $23,4693 \mathrm{~m} / \mathrm{s}$. Pada parameter packet loss kapasitas 20, 50 dan 100 node sama-sama memiliki nilai terendah yaitu sebesar $0,0000 \%$. Sedangkan pada parameter routing overhead menunjukkan kapasitas 100 node memiliki nilai terendah yaitu sebesar 5,3674\%.

\subsection{Analisa Hasil Pengujian Sistem}

Untuk hasil analisa skenario routing protokol DSR didapatkan nilai dimana konsumsi energi yang dibutuhkan pada kapasitas 50 node lebih hemat dengan nilai sebesar 17,0173 joule. Pada parameter packet delivery ratio menunjukkan dengan kapasitas 100 node memiliki nilai tertinggi yaitu 42,50000\%. Pada parameter average end-to-end delay menunjukkan jaringan dengan kapasitas 50 node memiliki delay terendah yaitu sebesar $11,8511 \%$. Pada parameter packet loss kapasitas 100 node memiliki nilai terendah yaitu sebesar 57,5000\%. Sedangkan pada parameter routing overhead menunjukkan kapasitas 100 node memiliki nilai terendah yaitu sebesar 5,0712\%.

Untuk hasil analisa skenario routing protokol DSDV didapatkan dimana konsumsi energi yang dibutuhkan pada kapasitas 10 node lebih hemat dengan nilai sebesar 0,9701 joule. Pada parameter packet delivery ratio menunjukkan dengan kapasitas 20 node memiliki nilai tertinggi yaitu $1,7544 \%$. Pada parameter average end-to-end delay semua jaringan menunjukkan sebesar 0,0000\%. Pada parameter packet loss kapasitas 20 node memiliki nilai terendah yaitu sebesar $98,2456 \%$. Sedangkan pada parameter routing overhead menunjukkan kapasitas 100 node memiliki nilai terendah yaitu sebesar $4,6707 \%$.

Sedangkan untuk hasil analisa skenario routing protokol ZRP didapatkan dimana konsumsi energi yang dibutuhkan pada kapasitas 20 node lebih hemat dengan nilai sebesar 1,9787 joule. Pada parameter packet delivery ratio menunjukkan dengan kapasitas 20, 50 dan 100 node sama-sama memiliki nilai tertinggi yaitu $100,0000 \%$. Pada parameter average end-to-end delay menunjukkan dengan kapasitas 100 node memiliki nilai sebesar 23,4693\%. Pada parameter packet loss kapasitas 20, 50 dan 100 node sama-sama memiliki nilai terendah yaitu sebesar $0,0000 \%$. Sedangkan pada parameter routing overhead menunjukkan kapasitas 100 node memiliki nilai terendah yaitu sebesar 5,3674\%.

\section{PENUTUP}

\subsection{Kesimpulan}

Skripsi ini menghasilkan beberapa kesimpulan sebagai berikut :

Analisis performansi dengan melakukan simulasi menggunakan Network Simulator 2 didapatkan hasil 
parameter konsumsi energi paling hemat pada routing protokol DSDV skenario 10 node dengan 0,9701 joule. Untuk parameter delay mendapatkan hasil $0 \mathrm{~m} / \mathrm{s}$. Sedangkan pada parameter routing overhead pada skenario 100 node mendapatkan hasil 4,6707 \%. Karena routing protokol DSDV bersifat proaktif yang selalu melakukan update tabel routing setiap ada node yang berpindah tempat, sehingga protokol ini hanya membutuhka konsumsi energi yang sedikit dan tidak membutuhkan delay untuk mencari rute baru dan routing overhead akan rendah. Pada hasil parameter Packet Delivery Ratio (PDR), ZRP memiliki nilai tertinggi pada parameter ini yaitu pada skenario 20, 50 dan 100 node dengan hasil $100 \%$. Berarti dalam hal keberhasilan routing protokol ZRP dalam mengirimkan paket sangat maksimal, sehingga secara otomatis parameter packet loss akan rendah yaitu $0 \%$.

\subsection{Saran}

Saran penulis terhadap skripsi ini adalah sebagai berikut:

1. Dalam pengembangan selanjutnya diharapkan menggunakan protokol routing yang lain yaitu AODV (Ad Hoc On Demand Distance Vector), FSDSR (Flow State in the Dynamic Source Routing) pada jenis routing protokol reaktif, OLSR (Optimized Link State Routing Protokol), B.A.T.M.A.N (Better Approach to Mobile Ad Hoc Network) pada jenis routing protokol proaktif, dan HWMP (Hybrid Wireless Mesh Protokol) pada jenis routing protokol hybrid dan menggunakan parameter pengukuran yang berbeda yaitu throughput, normalized routing load.

2. Melakukan penelitian dengan melakukan pengembangan berupa penambahan metode pada library protokol routing.

\section{DAFTAR PUSTAKA}

Al-Radhaan A. Mznah, Al-Dhelaan A. (2010), "Efficient Route Discovery Algorithm for MANETs". Proceedings of IEEE International Conference on Networking, Architecture, and Storage.

Amilia, F., Marzuki, Agustina. (2014), “Analisis Perbandingan Kinerja Protokol Dynamic Source Routing (DSR) dan Geographic Routing Protokol (GRP) Pada Mobie Ad Hoc Network (MANET)". Jurnal Sains, Teknologi dan Industri, Vol. 12, No. 1, pp. UIN Sultan Syarif Kasim, Riau.

Anggraini, S.D., Kukuh Nugroho, Eko Fajar Cahyadi. (2017), “Analisis Perbandingan Performasi Protokol Routing AODV dan DSR Pada Mobile Ad-Hoc Network (MANET)". Jurusan Teknik Telekomunikasi Sekolah Tinggi Teknologi Telematika Telkom, Purwokerto.

Corson, S., Macker, J. (1999), "Mobile Ad Hoc Networking (MANET) : Routing Protokol
Performance Issues and Evaluation Considerations". Naval Research Laboratory. University of Maryland.

Fahriani, N., Supeno Djanali, Ary Mazharuddin Shiddiqi (2012), "Efisiensi Rute Pada Protokol DSR Menggunakan PA-Short”. Tesis Magister, Institut Teknologi Sepuluh Nopember, Surabaya.

Ferdianto, I.A. (2013), “Comparative Of Energy Consumption Of Destination Sequenced Vector Protocol With Optimized Routing Link State On Mobile Ad Hoc Network". Informatics Engineering Department Faculty of Science and Technology Sanata Dharma University, Yogyakarta.

Imawan, D. (2009), “Analisis Kinerja Pola-Pola Trafik Pada Beberapa Protokol Routing Dalam Jaringan MANET”. Institut Teknologi Sepuluh Nopember, Surabaya.

Johnson, D.B., David A. Maltz, and Josh Broch. (2001), "DSR: The Dynamic Source Routing Protocol for Multi-Hop wireless Ad Hoc Networks". Computer Science Department Carnegie Mellon University Pittsburgh, PA Chapter 5 pp 139-172, Addison-wesley.

Ms.S.Suganya., Dr.S.Palaniammal. (2012), “An Optimized Energy Consumption Algorithm for MANET". Procedia Engineering 38 (2012) 903910. SciVerse ScienceDirect. Dept. of Computer Applications, TamilNadu College of Engineering, Coimbatore, India.

Permana, Y.P., Purwanto, Y., Wahidah, I. 2010. "Analisis Pengaruh Penggunaan Protokol Routing AODV, DSDV, dan ZRP Pada Performansi Jaringan Ad hoc Hibrid”. Teknik Telekomunikasi, Teknik Elektro Universitas Telkom.

Rudhyanto, P.F. (2016), “Analisis Perbandingan Unjuk Kerja Protokol Proaktif DSDV Terhadap Protokol Routing Reaktif DSR Pada Jaringan MANET". Program Studi Teknik Informatika, Fakultas Sains dan Teknologi Universitas Sanata Dharma, Yogyakarta.

Sasongko, S.A., Sukiswo, Ajub Ajulian Zahra. (2012), "Analisis Performansi dan Simulasi Protokol ZRP (Zone Routing Protocol) Pada MANET (Mobile Ad hoc Network) Dengan Menggunakan NS-2". Jurusan Teknik Elektro, Fakultas Teknik, Universitas Diponegoro. 
INDEXIA: Informatic and Computational Intelegent Journal

Aris Ismail, Misbah, Nuniek Fahriani

Analisis Performansi Routing Protokol Dsr, Dsdv Dan Zrp Pada Manet Menggunakan Network Simulator 2

Sidharta, Y., Damar Widjaja. (2013), "Perbandingan Unjuk Kerja Protokol Routing Ad Hoc OnDemand Distance Vector (AODV) dan Dynamic Source Routing (DSR) Pada Jaringan MANET"'. Jurnal Teknologi, Volume 6 Nomor 1 Hal 83-89. Universitas Sanata Dharma, Yogyakarta.

Venkatesh, C., Yadaiah, N., Natarajan, M. (2005), "Source Routing Protocol Using Fuzzy Logic Concepts For Ad Hoc Networks", Academic Open Internet Journal, Volume 15.

Wahanani, H.E. (2013), “Kinerja Protokol DSR Pada Jaringan MANET Dengan Metode Node Disjoint and Alternative Multipath Routing". Seminar Nasional Teknik Informatika (SANTIKA) 2013 pp 33-41. Universitas Pembangunan Nasional Veteran, Surabaya.

Wibowo, A.P., M.Zuliansyah, Andrian Rakhmatsyah. (2008), “Analisis Strategi Proactive Routing Protocol dan Reactive Routing Protocol Pada Mobile Ad Hoc Network". Universitas Telkom.

Yanuar, G.C. (2016), “Analisis Perbandingan Unjuk Kerja Protokol Routing Proaktif B.A.T.M.A.N Terhadap Routing Protokol Proaktif OLSR Pada Jaringan MANET', Jurusan Teknik Informatika Fakultas Sains dan Teknologi Universitas Sanata Dharma, Yogyakarta. 